\title{
A Role for T-Lymphocytes in Human Breast Cancer and in Canine Mammary Tumors
}

\author{
Maria Isabel Carvalho, ${ }^{1}$ Isabel Pires, ${ }^{1}$ Justina Prada, ${ }^{1}$ and Felisbina L. Queiroga ${ }^{2,3,4}$ \\ ${ }^{1}$ CECAV, Department of Veterinary Sciences, University of Trás-os-Montes and Alto Douro, 5001-801 Vila Real, Portugal \\ ${ }^{2}$ Department of Veterinary Sciences, University of Trás-os-Montes and Alto Douro, 5001-801 Vila Real, Portugal \\ ${ }^{3}$ Center for the Study of Animal Sciences (CECA), University of Porto, Porto, 4480 Vila do Conde, Portugal \\ ${ }^{4}$ Center for Research and Technology of Agro-Environment and Biological Sciences (CITAB), \\ University of Trás-os-Montes and Alto Douro, 5001-801 Vila Real, Portugal \\ Correspondence should be addressed to Felisbina L. Queiroga; fqueirog@utad.pt
}

Received 27 April 2013; Accepted 18 November 2013; Published 2 February 2014

Academic Editor: Monica Fedele

Copyright (C) 2014 Maria Isabel Carvalho et al. This is an open access article distributed under the Creative Commons Attribution License, which permits unrestricted use, distribution, and reproduction in any medium, provided the original work is properly cited.

\begin{abstract}
Chronic inflammation in the tumor microenvironment has a prominent role in carcinogenesis and benefits the proliferation and survival of malignant cells, promoting angiogenesis and metastasis. Mammary tumors are frequently infiltrated by a heterogeneous population of immune cells where T-lymphocytes have a great importance. Interestingly, similar inflammatory cell infiltrates, cytokine and chemokine expression in humans and canine mammary tumors were recently described. However, in both species, despite all the scientific evidences that appoint for a significant role of T-lymphocytes, a definitive conclusion concerning the effectiveness of T-cell dependent immune mechanisms has not been achieved yet. In the present review, we describe similarities between human breast cancer and canine mammary tumors regarding tumor T-lymphocyte infiltration, such as relationship of TILs and mammary tumors malignancy, association of ratio CD4+/ CD8+ T-cells with low survival rates, promotion of tumor progression by Th2 cells actions, and association of great amounts of Treg cells with poor prognostic factors. This apparent parallelism together with the fact that dogs develop spontaneous tumors in the context of a natural immune system highlight the dog as a possible useful biological model for studies in human breast cancer immunology.
\end{abstract}

\section{Introduction}

The mammalian immune system comprises a coordinated and finely controlled series of interactions involving cells and molecules and has an essential role on species survival and adaptation all over the years [1]. The immune system has the important task of distinguishing between "self" and "nonself", providing protection against foreign pathogens, maintaining at the same time tolerance to self-antigens $[2,3]$.

Cancer is a progressive process that arises from a welldefined step where somatic cells acquire activating (oncogenes) or deactivating (tumor suppressor genes) mutations $[4,5]$. All types of cancer are caused by the progressive and uncontrolled growth of transformed cells and the control of this disease requires the ablation and destruction of all the malignant cells without damaging the patient. To attain this assignment the own body has to distinguish between the cells of the tumor and other cellular counterparts $[3,6]$. However, unfortunately, many tumors continue to grow progressively and expand, which demonstrates that immune system is not always effective and fails on its protective role against tumor development $[3,7]$.

Decades of intensive investigation left clear that the interplay between immunity and cancer is complex [8]. One example of this high complexity is the phenomena of "Cancer Immunoediting." Cancer cells constantly modulate the host antitumor immune response in a process called immunoediting. During this process, the balance between antitumor and tumor-promoting immunity can be tilted to protect against the neoplasia development or, on the contrary, to support tumor growth. Immunoediting is characterized as a three-phase process including elimination phase 
(immunosurveillance), equilibrium phase, and escape phase [5]. Therefore, the immune system can release factors that promote neoplastic cells survivor, growth, and invasion. Thus, paradoxically, immune system acts as an extrinsic tumorsuppressor but can also promote cancer initiation, promotion, and progression [9].

\section{Chronic Inflammation and Cancer}

The role of chronic inflammation in cancer was first proposed by Rudolf Virchow in 1863, when he observed the presence of leucocytes in neoplastic tissues. Virchow postulated that an inflammatory milieu promotes a cellular environment that drives the initiation and development of carcinogenesis (reviewed in $[10,11]$ ).

Inflammatory responses play a crucial role at different stages of tumor development $[12,13]$. Innate immune cells that infiltrate tumors participate in an extensive and dynamic crosstalk with cancer cells and some of the molecular events that mediate this dialog have been revealed $[6,14]$. The most relevant molecular mechanisms include increased production of proinflammatory mediators, such as cytokines, chemokines, reactive oxygen intermediates, increased expression of oncogenes, COX-2 (cyclooxygenase2), 5-LOX (5-lipoxygenase), and MMPs (matrix metalloproteinases), and proinflammatory transcription factors such as NF- $\kappa \mathrm{B}$ (nuclear factor $\kappa \mathrm{B}$ ), STAT3 (signal transducer and activator of transcription 3), AP-1 (activator protein 1), and HIF- $1 \alpha$ (hypoxia-inducible factor $1 \alpha$ ). These proinflammatory mediators potentiate tumor cell proliferation, transformation, metastasis, invasion, angiogenesis, chemoresistance, and radioresistance [11, 15-17].

So, why does inflammation potentiate cancer development rather than protect against it? In fact, chronic inflammation is considered important in the promotion of cellular proliferation and cancer progression by enhancing angiogenesis and tissue invasion $[5,13]$, releasing products that promote carcinogenesis in nearby cells and accelerating genetic mutations through a state of malignancy [7]. Finally, through cancerderived products, immune and regulatory cells are recruited and the weak tumor antigenicity subverts immune cells in order to support cancer progression $[5,18]$.

\section{Adaptive Immunity and Cancer Development: A Role for T-Lymphocytes}

In neoplastic lesions, the role of infiltrating T-lymphocytes is often paradoxical. Despite the evidence that the responses of T-lymphocyte can destroy tumor cells "in situ," these responses appear to be frequently ineffective in the elimination of the established cancer $[19,20]$. In fact, patients with cancer present a deficient immune response to tumor antigens. However, this deficient immune response is clearly different from immunosuppression observed in patients receiving high doses of corticosteroids and/or chemotherapy. The term "immune dysfunction" seems the most appropriate to describe the changes observed. The mechanisms that support this "immune disorder" include barriers that prevent recognition of the tumor by immune cells and also lymphocyte dysfunction [21].

The barriers that prevent recognition of the tumor by immune cells include several mechanisms such as sequestration of tumor associated antigens and major histocompatibility complex (MHC) molecules, loss of costimulatory molecules and other molecules required by cytotoxic $\mathrm{T}$ cells. These mechanisms represent a barrier for the total elimination of tumor $[19,22,23]$. In respect to the lymphocyte dysfunction that seems to be present in cancer patients, a tumor-directed immune response involving cytotoxic CD8+ T-cells, T helper 1 (Th1) cells, and natural killer (NK) cells appears to protect against tumor development and progression. Contrarily, the immune responses that involves $\mathrm{B}$ cells, the activation of chronic humoral immunity and/or a T helper 2 (Th2) polarized response and polarized innate inflammatory cells in the tumor, can promote tumor development and progression. This balance between a protective cytotoxic response and a harmful humoral or Th2 response can be regulated systemically by the general immune status of the individual $[20,24]$.

In this context, the question that arises is what is the reason why the responses mediated by $C D 8+$ cytotoxic $T$ lymphocytes are not effective in eradicating the tumor and how can the CD4+ T-cells be involved in neoplastic progression of this disease?

A part of the response has already been described above and is related to tumor escape mechanisms from cytotoxic CD8+ T-cells action. Another important mechanism appears to be related to the polarity of the responses of CD4+ Tcells in relation to the primary site of cancer and/or their distant metastases [24] and the imbalance of the normal ratio of Th1/Th2 cells [25].

CD4+ T-cells are activated in response to soluble factors and can be classified into categories, Th1 and Th2. After stimulation, the Thl cells secrete interferon gamma (IFNg), transforming growth factor beta $(\mathrm{TGF} \beta)$, tumor necrosis factor alpha (TNF), and interleukin 2 (IL-2). These cytokines cooperate with the functions of cytotoxic CD8+ T-cells, producing a tumoricidal activity. In contrast, Th 2 cells express interleukin (IL) 4, 5, 6, 10, and 13 that induce anergy of T-cells and loss of cytotoxicity, while increasing the humoral immunity (lymphocyte $\mathrm{B}$ function). Thus, Thl cell responses benefit antitumor immunity, whereas Th2 cell responses produce a down-regulation of antitumor cell mediated immunity and increase the humoral protumourigenic responses [24, 26, 27].

Although the immune dysfunction in patients with cancer is now better understood with the perception of Th1 and Th2 regulation, what is responsible for this dysfunction remains to be determined. One possibility is that the number of Th1 cells or their precursors are reduced, decreasing one line of defense against cancer progression and metastasis. Another possibility is the important role played by regulatory T-cells and immature myeloid cells in the antitumor immune suppression observed in patients with breast cancer and other type of neoplasms $[25,28]$.

Regulatory T-cells (Treg cells) are a distinct group of lymphocytes with immunosuppressive properties that usually maintain immune tolerance [29]. Treg cell suppressive 
activity is beneficial by restricting $\mathrm{T}$ cell response against self-antigens and preventing inflammatory and autoimmune diseases. In cancer, their inhibitory role in limiting immune response against "pseudo-self antigens" from tumor origin avoids an effective antitumoral immune response and often culminates into negative outcomes for the patient. These cells may play an important deleterious role in cancer immunopathology due to their potent suppressive activity of both T-cell activation and effector functions [20, 30, 31].

Immature myeloid cells express MHC class I molecules suggesting that they can induce cytotoxic T-cells anergy by binding to T-cell receptor (TCR) complex in absence of costimulatory signals $[32,33]$.

In the last years, a new subset of CD4+ (helper) Tcells, termed Th17 cells, has been characterized. Th17 subset secretes IL-17, IL-21, and IL-22 and plays critical roles in the pathogenesis of inflammatory and autoimmune diseases, as well as in host protection against pathogens. Although some data suggest the importance of Th17 cells for tumor immunity, conclusions regarding the functional role of Th17 cells remain controversial [34-36]. Even though some studies indicate that mouse Th17 cells support a positive anti-cancer immunity, the Th17 cells with intratumoral location are probably responsible for chronic tissue inflammation and appear to have a tumorpromoting effect $[35,37,38]$.

\section{T-Lymphocytes and Human Breast Cancer: Friends or Foes?}

In humans, the study of the inflammatory infiltrate, mainly T-lymphocytes, has been subject of great interest associated not only with breast cancer $[19,23,39]$, but also with other types of neoplasias, including seminoma [40, 41], melanoma $[42,43]$, colorectal $[44,45]$, cervical [46], ovarian [47, 48], urothelial [49], and gastric cancer [50].

In breast cancer, an important role has been attributed to inflammatory cells, as well as cytokines produced by them. A large number of observations suggest that inflammatory cells are not "innocent spectators," but, contrarily, they might conspire with the tumor cells favoring tumor development and progression [8]. However, the prognostic significance of infiltrating T-lymphocytes is still subject to considerable debate [24,51], because no definitive conclusions have been reached so far. The T-lymphocytes infiltrate appear, according to some researchers, associated with a better prognosis, whereas in other cases is related to a decline in overall survival. Table 1 illustrates some of the most relevant studies in this area in the last two decades.

More recently, investigations that focus on understanding the functions of Treg cells and Th17 cells in mammary carcinogenesis have been published; however, the results of the various studies are also quite controversial [69-71].

Lee and collaborators [69] investigated, by immunohistochemistry, whether the presence of FOXP3-positive Treg cells was associated with prognostic factors, such as stage or histologic grade. FOXP3-positive Treg cells were, in this study, an independent prognostic factor for overall survival and progression free survival. The improved survival times were associated with highly infiltrating FOXP3-positive Treg cells.

Another study, on the contrary, showed that the increased number of Foxp3 Treg cells was significantly correlated with lymph node metastasis and immunopositivity for Ki-67, which indicates a probable relationship with a worse prognosis. [70].

Wang and colleagues assessed the Th17 and Treg cells by flow cytometry and observed that Th17 and Treg cells accumulation in the tumor microenvironment of breast cancer occurred in early stages of disease. With tumor progression, Th17 cell infiltration gradually decreased and there was accumulation of Treg cells [71]. So, this last study indicates that an increase in the number of Treg cells is associated with tumor progression.

The apparent controversy among distinct studies emphasizes the need for further research on this topic. A clear understanding about the role of T-lymphocytes in breast cancer is essential for the development of new therapeutic strategies in a near future.

\section{T-Lymphocyte Infiltrate in Canine Mammary Tumors}

Canine mammary tumors are a spontaneous neoplasia that occurs frequently in the clinical practice $[72,73]$. Despite the high number of studies published on this subject in the last decades, little is known about the role of tumor inflammatory infiltrate in cancer development and/or progression. In dogs, the first studies focused on inflammation and cancer have been performed in other type of tumors including transmissible venereal sarcoma [74], benign oral papilloma [75], cutaneous histiocytoma [76], and seminomas [77]. Studies investigating the role of inflammation in canine mammary tumors were only recently published (Table 2) [78-83].

In canine transmissible venereal sarcoma, the quantity of T-lymphocytes is higher in the group of tumors that exhibit spontaneous regression or stable growth, comparatively with the tumors that exhibit a progressive growth [74]. In canine oral papilloma, similar to humans [84], the maximum number of T-cells that infiltrate the tumor occurs during rapid tumor regression [75]. In canine cutaneous histiocytoma, in the same way, a lymphocytic infiltrate represents the morphological expression of one antitumor immune response, which correlates with observations of spontaneous regression "in vivo" [76, 85]. In turn, in canine seminomas [77], in accordance with what occurs in human seminomas [40,41], infiltrating lymphoid cells consist mainly in T-lymphocytes, especially CD8+ cells, which means that the reaction of the body against neoplastic cells is mainly cytotoxic. This, together with the number of MHC I positive cells and a high amount of antigen presenting cells observed, suggests, according to the authors, that inflammatory cells exhibit a role in antitumor response [77]. This might explain the biological behavior of these tumors that rarely metastasize and the favorable prognosis that often presents. Interestingly, in 2007, Horiuchi and collaborators [86] refer that in animals with cancer, a smaller amount of Thl cells and a significant 


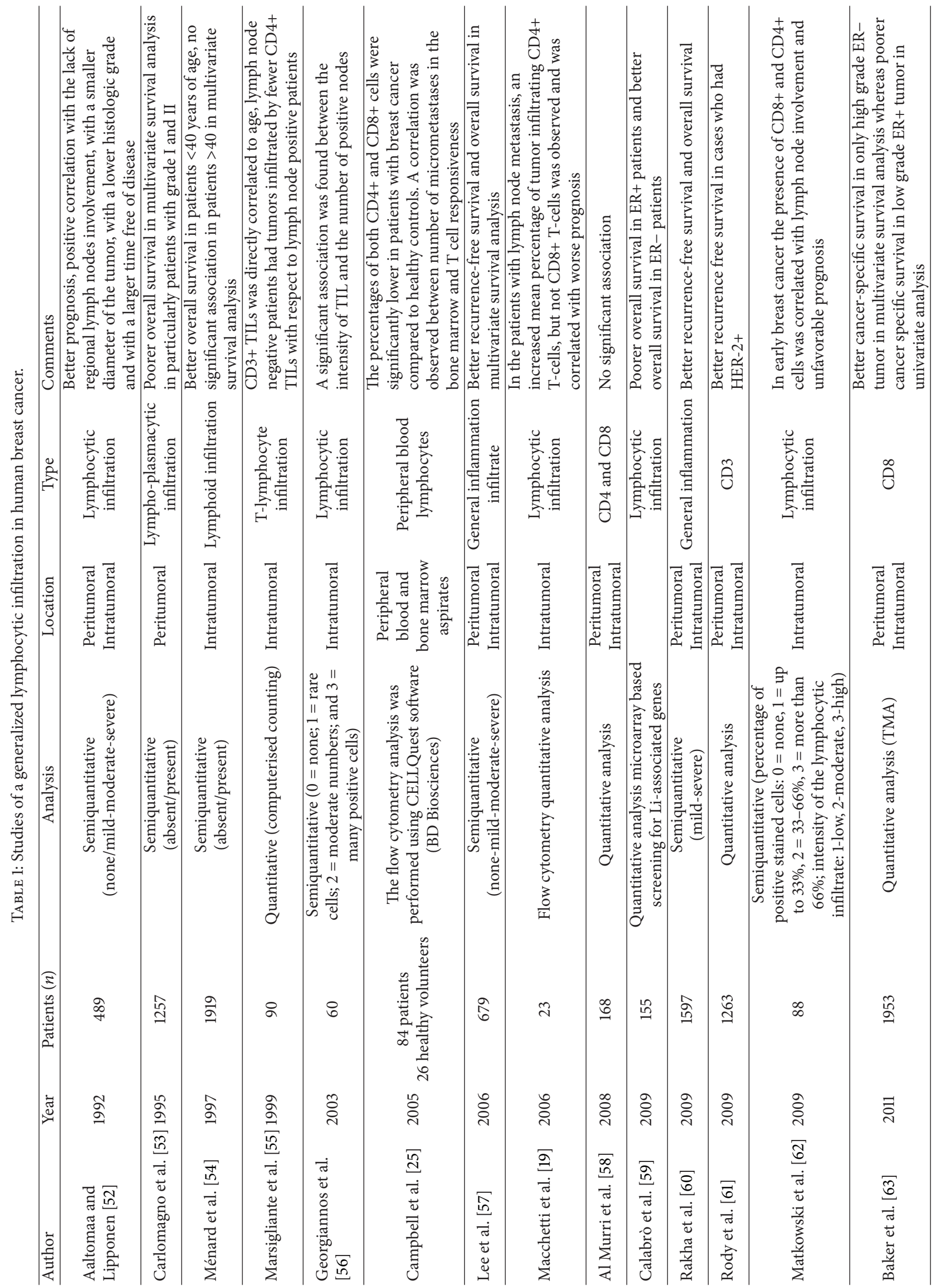




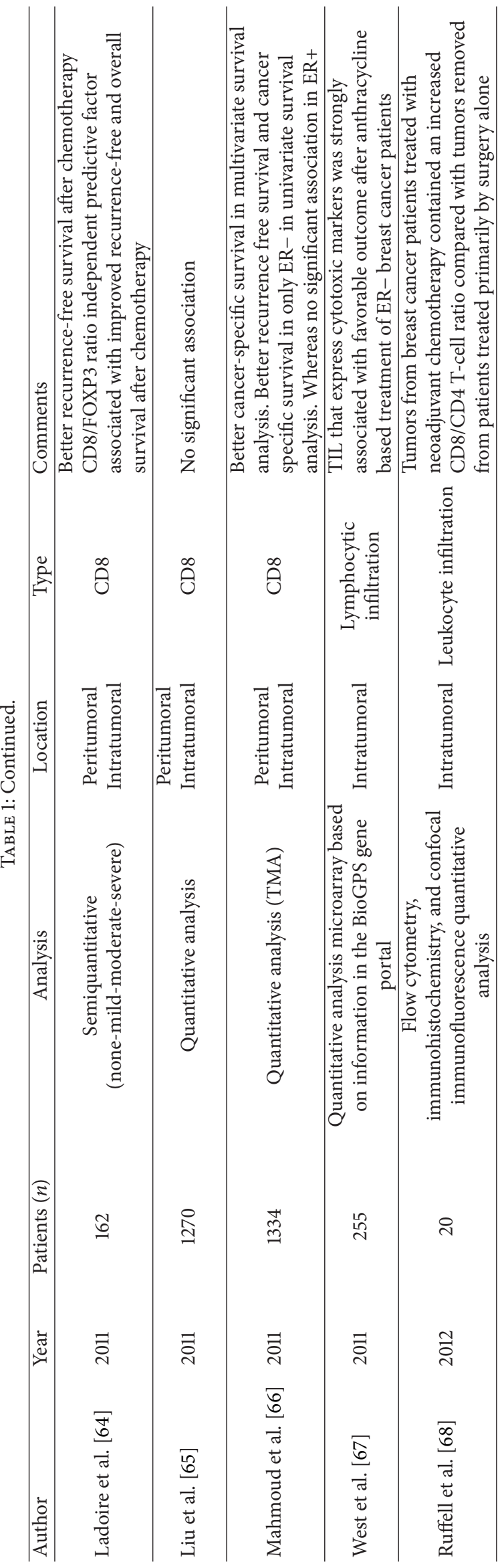


TABLE 2: Studies of T-lymphocytic infiltrate in Canine mammary tumors (CMT).

\begin{tabular}{|c|c|c|c|c|}
\hline Author & Year & Patients $(n)$ & Type & Comments \\
\hline Estrela-Lima et al. [78] & 2010 & 51 & T-lymphocyte infiltration & $\begin{array}{l}\text { Animals with high proportions of CD4+ and low CD8+ T-cells } \\
\text { had lower survival rates }\end{array}$ \\
\hline Kim et al. [79] & 2010 & 58 & T-lymphocyte infiltration & $\begin{array}{l}\text { Association between the expression of TILs, cytokines, and } \\
\text { mutation of BRCA1 suggests that all of these factors may play a } \\
\text { role in tumor progression }\end{array}$ \\
\hline Carvalho et al. [80] & 2011 & 57 & T-lymphocyte infiltration & $\begin{array}{l}\text { Tendency for an association of a higher number of CD3+ TILs } \\
\text { and a shorter overall survival. CD3+ T-lymphocytes in the } \\
\text { adnexal nontumoral mammary gland revealed a statistically } \\
\text { significant relationship with overall survival }\end{array}$ \\
\hline Saeki et al. [81] & 2012 & 140 & Lymphocytic infiltration & Relationship of TILs and canine mammary tumors malignancy \\
\hline Kim et al. [82] & 2012 & 37 & Regulatory T-cells (Treg) & $\begin{array}{l}\text { The number of Treg cells is increased in tumors with poor } \\
\text { prognostic factors, such as high histological grade, lymphatic } \\
\text { invasion, and necrosis }\end{array}$ \\
\hline Kim et al. [83] & 2013 & 47 & Lymphocytic infiltration & $\begin{array}{l}\text { Intense lymphocyte infiltration was associated with aggressive } \\
\text { histologic features (higher histologic grade; lymphatic invasion) }\end{array}$ \\
\hline
\end{tabular}

larger amount of Th2 cells, compared to healthy ones, was observed. Considering that Th2 cells have an action that promotes tumor progression, these results have come refute what is already known in human works and relaunch the interest in this subject in dogs.

In canine mammary tumors, as previously stated, there are only a very limited number of studies, all of them recently published, that focus on effect of T-lymphocytes infiltrate and malignancy [78-83]. In malignant mammary tumors, abundant lymphocyte infiltrates are frequently found, but the characteristics associated with lymphocyte infiltration in these tumors remain largely unknown. As in humans, the controversy among distinct reports remains an important issue to be clarified (Table 2).

According to Estrela-Lima and collaborators [78], lymphocytes represent the predominant cell type in the tumor infiltrate. The relative percentage of CD4+ T-cells was significantly greater in metastasized tumors, while the percentage of CD8+ T-cells was higher in cases without metastasis. Consequently, the CD4+/CD8+ ratio was significantly increased in cases with metastasis and was associated to lower survival rates. Authors defend that the intensity of lymphocytic infiltrate and the CD4+/CD8+ ratio may represent important survival prognostic biomarkers for canine mammary carcinomas.

In one study performed by Kim and colleagues [79], immunohistochemistry, immunoblotting, and reverse transcriptase-polymerase chain reaction were used to evaluate tumor infiltrating lymphocytes (TILs) and the presence of related cytokines, as well as the expression of breast cancer susceptibility gene-1 (BRCA1). The results of this study revealed a correlation between expression of interleukin (IL)1 and IL- 6 and tumor metastasis. An association among the expression of TILs, cytokines, and mutation of BRCA1 was also verified, suggesting that all of these factors may play a role in tumor progression.

In another study developed by our team [80], CD3+ Tlymphocytes were evaluated in three distinct areas: within the tumor, in the periphery of the tumor and in the adnexal non-tumoral mammary gland. We observed a tendency towards an association of a higher number of CD3+ tumor infiltrating T-lymphocytes and a shorter overall survival. However, interestingly, only for CD3+ T-lymphocytes in the adnexal non-tumoral mammary gland, a statistically significant relationship was observed, with a higher number of lymphocytes conferring a reduced overall survival. This could indicate that CD3+ T-lymphocytes in adnexal nontumoral mammary gland were implicated in tumor progression and survival, showing that its protumourigenic immune responses may somehow be the starting point for the growth and progression of tumor cells.

Saeki and collaborators [81] accessed the number of tumor infiltrating T-lymphocytes, B-lymphocytes, and antigen presenting cells by immunohistochemistry. As a result, the authors found a statistically significant increase in the number of intratumoral T-lymphocytes in malignant tumors compared with benign ones. The results of this study indicate a positive relationship between a high number of TILs and increased canine mammary tumors malignancy.

Very recently, Kim and colleagues [83] demonstrated, by immunohistochemistry, that the degree of lymphocyte infiltration was significantly higher in canine mammary carcinomas with lymphatic invasion and high histologic grade, suggesting the importance of lymphocytes on tumor aggressiveness and greater malignant behavior.

Treg cells, whose activity is closely associated with the transcription factor FOXP3, have a suppressive action on T-lymphocytes antitumor responses $[87,88]$. In dog, there are few studies that focus on the action of Treg cells in tumor development and progression [82, 89-91]. Dogs with cancer had increased numbers of Treg cells in their peripheral blood and tumor-draining lymph nodes compared to healthy animals [89].

In dog mammary tumors, a recent study by Kim and Colleagues [82] described abundant Treg cells associated with high histological grade and lymphatic invasion. The number of Treg cells infiltrating intratumoral areas was markedly increased in tumors with poor prognostic factors, such as 


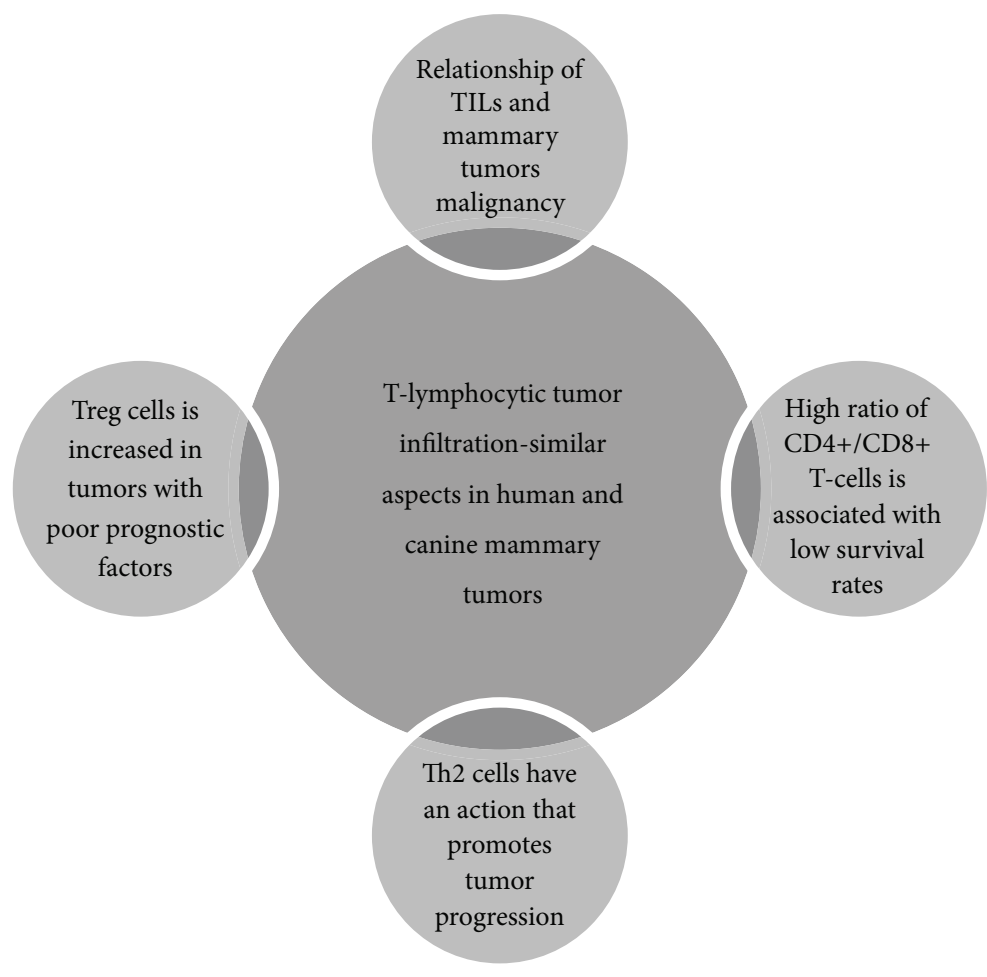

FIGURE 1: Similarities between human breast cancer and canine mammary tumors regarding tumor T-lymphocyte infiltration.

high histological grade of malignancy, presence of lymphatic invasion, and presence of tumoral necrosis. These findings suggest that Treg cells might play a key role in canine mammary tumors progression. Furthermore, the amount of intratumoral Treg cells may provide a new prognostic factor when assessing survival times, which may in turn lead to the development of new immunologic therapies.

The studies described above, concerning canine mammary tumors, describe results that are in agreement with those from studies already published in human breast cancer which may be an indication of similar cancer immunologic aspects between the two species (Figure 1).

\section{Final Remarks}

The dog has been proposed, by various authors and throughout several decades, as a model for the study of spontaneous malignancies in humans. This hypothesis is supported by the knowledge that development of spontaneous tumors in dogs and humans is a phenomenon highly incident, sharing many features: histological appearance, tumor genetics, molecular targets, biological behavior, and response to conventional therapy [92-94]. The recent sequencing of the canine genome and the evidence of its similarity to the human counterpart emphasized even more the dog as an attractive model for cancer research $[73,95,96]$.

Breast cancer remains a major clinical challenge with considerable mortality both in humans and dogs [72, 97]. Scientific evidences support that, in both species, alterations of inflammatory components within the tumoral microenvironment have a significant role during important steps of carcinogenesis. Additionally, dogs develop spontaneous tumors in the context of a natural immune system [94] which make them an attractive and viable target for immune therapeutic modulation $[5,8,80,97,98]$.

In the present review, we describe similarities between human breast cancer and canine mammary tumors regarding tumor T-lymphocyte infiltration, such as relationship of TILs and mammary tumors malignancy, association of ratio CD4+/CD8+ T-cells with low survival rates, promotion of tumor progression by Th2 cells actions, and association of great amounts of Treg cells with poor prognostic factors.

We believe that the current state of knowledge could be the basis for a broader and deeper discussion concerning the role of inflammation in dog tumors, especially in canine mammary cancer. Nevertheless, it remains to be clarified the role of the inflammatory infiltrate in tumors of high biological aggressiveness and thus elucidate the T-cell subtypes implicated in the progression of these neoplasms. The identification of specific subtypes and the clarification of the involved pathways, may serve as a basis for the establishment of new therapeutic strategies. In this sense, the development of an active immunization throughout the design of new anticancer-vaccines is expected both in humans and dogs.

In human breast cancer, it was already postulated that vaccination could induce an expansion of CD8+ cytotoxic Tlymphocytes capable of rejecting tumor cells via recognition of tumor-associated antigenic epitopes, located on the surface of cancer cells $[99,100]$. The development of anti-cancer 
vaccines may lead to the establishment of immunological memory, thereby preventing tumor recurrence with potential advantages in inducing antitumor immune responses in both species [11]. Dogs with mammary cancer develop metastatic disease in a shorter time compared with the humans, due to their smaller longevity which make them particularly good models for study the metastatic process and thus testing new therapeutic modalities [73, 94]. The similarities pointed out in this review support the use of dog with mammary cancer as a reliable biological model to study human breast cancer immunology, providing an attractive opportunity for therapeutic clinical studies in the scope of comparative oncology.

\section{Conflict of Interests}

The authors declare that there is no conflict of interests regarding the publication of this paper.

\section{Acknowledgments}

The work was supported partially by the Strategic Research Project Pest OE/AGR/UI0772/2011 and by a PhD scholarship SFRH/BD/78771/2011 both financed by the Portuguese Foundation for Science and Technology (FCT).

\section{References}

[1] R. J. Prestwich, F. Errington, P. Hatfield et al., "The immune system-is it relevant to cancer development, progression and treatment?" Clinical Oncology, vol. 20, no. 2, pp. 101-112, 2008.

[2] R. Medzhitov, "Origin and physiological roles of inflammation," Nature, vol. 454, no. 7203, pp. 428-435, 2008.

[3] K. E. de Visser, A. Eichten, and L. M. Coussens, "Paradoxical roles of the immune system during cancer development," Nature Reviews Cancer, vol. 6, no. 1, pp. 24-37, 2006.

[4] L. M. Coussens and Z. Werb, "Inflammatory cells and cancer: think different!," Journal of Experimental Medicine, vol. 193, no. 6, pp. F23-F26, 2001.

[5] M. D. Vesely, M. H. Kershaw, R. D. Schreiber, and M. J. Smyth, "Natural innate and adaptive immunity to cancer," Annual Review of Immunology, vol. 29, pp. 235-271, 2011.

[6] K. E. de Visser and L. M. Coussens, "The inflammatory tumor microenvironment and its impact on cancer development," Contributions to Microbiology, vol. 13, pp. 118-137, 2006.

[7] D. Hanahan and R. A. Weinberg, "Hallmarks of cancer: the next generation," Cell, vol. 144, no. 5, pp. 646-674, 2011.

[8] A. Ben-Baruch, "Host microenvironment in breast cancer development. Inflammatory cells, cytokines and chemokines in breast cancer progression: reciprocal tumor-microenvironment interactions," Breast Cancer Research, vol. 5, no. 1, pp. 31-36, 2003.

[9] M. C. Mihm Jr., C. G. Clemente, and N. Cascinelli, "Tumor infiltrating lymphocytes in lymph node melanoma metastases: a histopathologic prognostic indicator and an expression of local immune response," Laboratory Investigation, vol. 74, no. 1, pp. 43-47, 1996.

[10] S. Demaria, E. Pikarsky, M. Karin et al., "Cancer and inflammation: promise for biologic therapy," Journal of Immunotherapy, vol. 33, no. 4, pp. 335-351, 2010.
[11] G. Sethi, M. K. Shanmugam, L. Ramachandran, A. P. Kumar, and V. Tergaonkar, "Multifaceted link between cancer and inflammation," Bioscience Reports, vol. 32, no. 1, pp. 1-15, 2012.

[12] O. J. Finn, "Molecular origins of cancer: cancer immunology," The New England Journal of Medicine, vol. 358, no. 25, pp. 27042715, 2008.

[13] W. B. Morrison, "Inflammation and cancer: a comparative view," Journal of Veterinary Internal Medicine, vol. 26, no. 1, pp. 18-31, 2012.

[14] S. I. Grivennikov, F. R. Greten, and M. Karin, "Immunity, inflammation, and cancer," Cell, vol. 140, no. 6, pp. 883-899, 2010 .

[15] B. B. Aggarwal, S. Shishodia, S. K. Sandur, M. K. Pandey, and G. Sethi, "Inflammation and cancer: how hot is the link?" Biochemical Pharmacology, vol. 72, no. 11, pp. 1605-1621, 2006.

[16] B. B. Aggarwal and P. Gehlot, "Inflammation and cancer: how friendly is the relationship for cancer patients?" Current Opinion in Pharmacology, vol. 9, no. 4, pp. 351-369, 2009.

[17] F. Balkwill and A. Mantovani, "Cancer and inflammation: implications for pharmacology and therapeutics," Clinical Pharmacology and Therapeutics, vol. 87, no. 4, pp. 401-406, 2010.

[18] T. Hagemann, T. Lawrence, I. McNeish et al., "Re-educating' tumor-associated macrophages by targeting NF- $\kappa \mathrm{B}$," Journal of Experimental Medicine, vol. 205, no. 6, pp. 1261-1268, 2008.

[19] A. H. Macchetti, H. R. C. Marana, J. S. Silva, J. M. de Andrade, A. Ribeiro-Silva, and S. Bighetti, "Tumor-infiltrating CD4+ $\mathrm{T}$ lymphocytes in early breast cancer reflect lymph node involvement," Clinics, vol. 61, no. 3, pp. 203-208, 2006.

[20] G. Curigliano, "Immunity and autoimmunity: revising the concepts of response to breast cancer," Breast, vol. 20, supplement 3, pp. S71-S74, 2011.

[21] J. Finke, S. Ferrone, A. Frey, A. Mufson, and A. Ochoa, "Where have all the $\mathrm{T}$ cells gone? Mechanisms of immune evasion by tumors," Immunology Today, vol. 20, no. 4, pp. 158-160, 1999.

[22] A. J. Marrogi, A. Munshi, A. J. Merogi et al., "Study of tumor infiltrating lymphocytes and transforming growth factor-beta as prognostic factors in breast carcinoma," International Journal of Cancer, vol. 74, pp. 492-501, 1997.

[23] B. Sheu, W. Kuo, R. Chen, S. Huang, K. Chang, and S. Chow, "Clinical significance of tumor-infiltrating lymphocytes in neoplastic progression and lymph node metastasis of human breast cancer," Breast, vol. 17, no. 6, pp. 604-610, 2008.

[24] D. G. DeNardo and L. M. Coussens, "Inflammation and breast cancer. Balancing immune response: crosstalk between adaptive and innate immune cells during breast cancer progression," Breast Cancer Research, vol. 9, no. 4, article 212, 2007.

[25] M. J. Campbell, J. Scott, H. T. Maecker, J. W. Park, and L. J. Esserman, "Immune dysfunction and micrometastases in women with breast cancer," Breast Cancer Research and Treatment, vol. 91, no. 2, pp. 163-171, 2005.

[26] S. Goto, M. Sato, R. Kaneko, M. Itoh, S. Sato, and S. Takeuchi, "Analysis of Th1 and Th2 cytokine production by peripheral blood mononuclear cells as a parameter of immunological dysfunction in advanced cancer patients," Cancer Immunology Immunotherapy, vol. 48, no. 8, pp. 435-442, 1999.

[27] M. J. M. Gooden, G. H. de Bock, N. Leffers, T. Daemen, and H. W. Nijman, "The prognostic influence of tumour-infiltrating lymphocytes in cancer: a systematic review with meta-analysis," British Journal of Cancer, vol. 105, no. 1, pp. 93-103, 2011.

[28] A. Mantovani, F. Marchesi, C. Porta, A. Sica, and P. Allavena, "Inflammation and cancer: breast cancer as a prototype," Breast, vol. 16, supplement 2, pp. 27-33, 2007. 
[29] H. von Boehmer and C. Daniel, "Therapeutic opportunities for manipulating T(Reg) cells in autoimmunity and cancer," Nature Reviews Drug Discovery, vol. 12, pp. 51-63, 2013.

[30] S. Sakaguchi, K. Wing, Y. Onishi, P. Prieto-Martin, and T. Yamaguchi, "Regulatory T cells: how do they suppress immune responses?" International Immunology, vol. 21, no. 10, pp. 11051111, 2009.

[31] C. Tanchot, M. Terme, H. Pere et al., “Tumor-infiltrating regulatory T cells: phenotype, role, mechanism of expansion in situ and clinical significance," Cancer Microenvironment, vol. 6, no. 2, pp. 147-157, 2013.

[32] B. Almand, J. I. Clark, E. Nikitina et al., "Increased production of immature myeloid cells in cancer patients: a mechanism of immunosuppression in cancer," Journal of Immunology, vol. 166, no. 1, pp. 678-689, 2001.

[33] S. Ostrand-Rosenberg and P. Sinha, "Myeloid-derived suppressor cells: linking inflammation and cancer," Journal of Immunology, vol. 182, no. 8, pp. 4499-4506, 2009.

[34] K. S. Sfanos, T. C. Bruno, C. H. Maris et al., "Phenotypic analysis of prostate-infiltrating lymphocytes reveals T H17 and Treg skewing," Clinical Cancer Research, vol. 14, no. 11, pp. 3254-3261, 2008.

[35] F. Martin, L. Apetoh, and F. Ghiringhelli, "Controversies on the role of Th17 in cancer: a TGF-beta-dependent immunosuppressive activity?" Trends in Molecular Medicine, vol. 18, no. 12, pp. 742-749, 2012.

[36] J. Ye, R. S. Livergood, and G. Peng, "The role and regulation of human Th17 cells in tumor immunity," The American Journal of Pathology, vol. 182, pp. 10-20, 2013.

[37] I. Kryczek, M. Banerjee, P. Cheng et al., "Phenotype, distribution, generation, and functional and clinical relevance of Th17 cells in the human tumor environments," Blood, vol. 114, no. 6, pp. 1141-1149, 2009.

[38] S. V. Novitskiy, M. W. Pickup, A. E. Gorska et al., “TGF-beta receptor II loss promotes mammary carcinoma progression by Th17 dependent mechanisms," Cancer Discovery, vol. 1, pp. 430441, 2011.

[39] H. Kuroda, J. Tamaru, G. Sakamoto, K. Ohnisi, and S. Itoyama, "Immunophenotype of lymphocytic infiltration in medullary carcinoma of the breast," Virchows Archiv, vol. 446, no. 1, pp. 10-14, 2005.

[40] E. Yakirevich, O. Lefel, Y. Sova et al., "Fractalkine expression in human renal inflammation," Journal of Pathology, vol. 196, no. 1, pp. 85-90, 2002.

[41] S. R. Hadrup, O. Brændstrup, G. K. Jacobsen et al., "Tumor infiltrating lymphocytes in seminoma lesions comprise clonally expanded cytotoxic T cells," International Journal of Cancer, vol. 119, no. 4, pp. 831-838, 2006.

[42] F. Piras, R. Colombari, L. Minerba et al., "The predictive value of CD8, CD4, CD68 and human leukocyte antigen-D-related cells in the prognosis of cutaneous malignant melanoma with vertical growth phase," Cancer, vol. 104, no. 6, pp. 1246-1254, 2005.

[43] R. C. Taylor, A. Patel, K. S. Panageas, K. J. Busam, and M. S. Brady, "Tumor-infiltrating lymphocytes predict sentinel lymph node positivity in patients with cutaneous melanoma," Journal of Clinical Oncology, vol. 25, no. 7, pp. 869-875, 2007.

[44] F. Pagès, A. Berger, M. Camus et al., "Effector memory T cells, early metastasis, and survival in colorectal cancer," The New England Journal of Medicine, vol. 353, no. 25, pp. 2654-2666, 2005.
[45] J. Galon, A. Costes, F. Sanchez-Cabo et al., "Type, density, and location of immune cells within human colorectal tumors predict clinical outcome," Science, vol. 313, no. 5795, pp. 1960-1964, 2006.

[46] S. J. Piersma, E. S. Jordanova, M. I. E. van Poelgeest et al., "High number of intraepithelial CD8+ tumor-infiltrating lymphocytes is associated with the absence of lymph node metastases in patients with large early-stage cervical cancer," Cancer Research, vol. 67, no. 1, pp. 354-361, 2007.

[47] L. Zhang, J. R. Conejo-Garcia, D. Katsaros et al., "Intratumoral T cells, recurrence, and survival in epithelial ovarian cancer," The New England Journal of Medicine, vol. 348, no. 3, pp. 203213, 2003.

[48] M. Tomšová, B. Melichar, I. Sedláková, and I. Šteiner, "Prognostic significance of CD3+ tumor-infiltrating lymphocytes in ovarian carcinoma," Gynecologic Oncology, vol. 108, no. 2, pp. 415-420, 2008.

[49] P. Sharma, Y. Shen, S. Wen et al., "CD8 tumor-infiltrating lymphocytes are predictive of survival in muscle-invasive urothelial carcinoma," Proceedings of the National Academy of Sciences of the United States of America, vol. 104, no. 10, pp. 3967-3972, 2007.

[50] H. E. Lee, S. W. Chae, Y. J. Lee et al., "Prognostic implications of type and density of tumour-infiltrating lymphocytes in gastric cancer," British Journal of Cancer, vol. 99, no. 10, pp. 1704-1711, 2008.

[51] Z. M. Mohammed, J. J. Going, J. Edwards, and D. C. McMillan, "The role of the tumour inflammatory cell infiltrate in predicting recurrence and survival in patients with primary operable breast cancer," Cancer Treatment Reviews, vol. 38, pp. 943-955, 2012.

[52] S. Aaltomaa and P. Lipponen, "Prognostic factors in breastcancer (review)," International Journal of Oncology, vol. 1, pp. 153-159, 1992.

[53] C. Carlomagno, F. Perrone, R. Lauria et al., "Prognostic significance of necrosis, elastosis, fibrosis and inflammatory cell reaction in operable breast cancer," Oncology, vol. 52, no. 4, pp. 272-277, 1995.

[54] S. Ménard, G. Tomasic, P. Casalini et al., "Lymphoid infiltration as a prognostic variable for early-onset breast carcinomas," Clinical Cancer Research, vol. 3, no. 5, pp. 817-819, 1997.

[55] S. Marsigliante, L. Biscozzo, A. Marra et al., "Computerised counting of tumour infiltrating lymphocytes in 90 breast cancer specimens," Cancer Letters, vol. 139, no. 1, pp. 33-41, 1999.

[56] S. N. Georgiannos, A. Renaut, A. W. Goode, and M. Sheaff, "The immunophenotype and activation status of the lymphocytic infiltrate in human breast cancers, the role of the major histocompatibility complex in cell-mediated immune mechanisms, and their association with prognostic indicators," Surgery, vol. 134 , no. 5, pp. 827-834, 2003.

[57] A. H. S. Lee, C. E. Gillett, K. Ryder, I. S. Fentiman, D. W. Miles, and R. R. Millis, "Different patterns of inflammation and prognosis in invasive carcinoma of the breast," Histopathology, vol. 48, no. 6, pp. 692-701, 2006.

[58] A. M. Al Murri, M. Hilmy, J. Bell et al., "The relationship between the systemic inflammatory response, tumour proliferative activity, T-lymphocytic and macrophage infiltration, microvessel density and survival in patients with primary operable breast cancer," British Journal of Cancer, vol. 99, no. 7, pp. 1013-1019, 2008.

[59] A. Calabrò, T. Beissbarth, R. Kuner et al., "Effects of infiltrating lymphocytes and estrogen receptor on gene expression and 
prognosis in breast cancer," Breast Cancer Research and Treatment, vol. 116, no. 1, pp. 69-77, 2009.

[60] E. A. Rakha, M. Aleskandarany, M. E. El-Sayed et al., “The prognostic significance of inflammation and medullary histological type in invasive carcinoma of the breast," European Journal of Cancer, vol. 45, no. 10, pp. 1780-1787, 2009.

[61] A. Rody, U. Holtrich, L. Pusztai et al., "T-cell metagene predicts a favorable prognosis in estrogen receptor-negative and HER2positive breast cancers," Breast Cancer Research, vol. 11, no. 2, article R15, 2009.

[62] R. Matkowski, I. Gisterek, A. Halon et al., "The prognostic role of tumor-infiltrating CD4 and CD8 T lymphocytes in breast cancer," Anticancer Research, vol. 29, no. 7, pp. 2445-2451, 2009.

[63] K. Baker, J. Lachapelle, I. Zlobec, T. A. Bismar, L. Terracciano, and W. D. Foulkes, "Prognostic significance of CD8+ T lymphocytes in breast cancer depends upon both oestrogen receptor status and histological grade," Histopathology, vol. 58, no. 7, pp. 1107-1116, 2011.

[64] S. Ladoire, G. Mignot, S. Dabakuyo et al., "In situ immune response after neoadjuvant chemotherapy for breast cancer predicts survival," Journal of Pathology, vol. 224, no. 3, pp. 389400, 2011.

[65] F. Liu, R. Lang, J. Zhao et al., "CD8+ cytotoxic T cell and FOXP3+ regulatory $\mathrm{T}$ cell infiltration in relation to breast cancer survival and molecular subtypes," Breast Cancer Research and Treatment, vol. 130, no. 2, pp. 645-655, 2011.

[66] S. M. A. Mahmoud, E. C. Paish, D. G. Powe et al., “Tumorinfiltrating $\mathrm{CD} 8+$ lymphocytes predict clinical outcome in breast cancer," Journal of Clinical Oncology, vol. 29, no. 15, pp. 1949-1955, 2011.

[67] N. R. West, K. Milne, P. T. Truong, N. Macpherson, B. H. Nelson, and P. H. Watson, "Tumor-infiltrating lymphocytes predict response to anthracycline-based chemotherapy in estrogen receptor-negative breast cancer," Breast Cancer Research, vol. 13, no. 6, article R126, 2011.

[68] B. Ruffell, A. Au, H. S. Rugo, L. J. Esserman, E. S. Hwang, and L. M. Coussens, "Leukocyte composition of human breast cancer," Proceedings of the National Academy of Sciences of the United States of America, vol. 109, no. 8, pp. 2796-2801, 2012.

[69] S. Lee, E. Y. Cho, Y. H. Park, J. S. Ahn, and Y. H. Im, "Prognostic impact of FOXP3 expression in triple-negative breast cancer," Acta Oncologica, vol. 52, no. 1, pp. 73-81, 2013.

[70] S. T. Kim, H. Jeong, O. H. Woo et al., "Tumor-infiltrating lymphocytes, tumor characteristics, and recurrence in patients with early breast cancer," American Journal of Clinical Oncology, vol. 36, no. 3, pp. 224-231, 2013.

[71] J. Wang, D. Cai, B. Ma, G. Wu, and J. Wu, "Skewing the balance of regulatory T-cells and T-helper 17 cells in breast cancer patients," Journal of International Medical Research, vol. 39, no. 3, pp. 691-701, 2011.

[72] K. U. Sorenmo, R. Rasotto, V. Zappulli, and M. H. Goldschmidt, "Development, anatomy, histology, lymphatic drainage, clinical features, and cell differentiation markers of canine mammary gland neoplasms," Veterinary Pathology, vol. 48, no. 1, pp. 8597, 2011.

[73] F. L. Queiroga, T. Raposo, M. I. Carvalho, J. Prada, and I. Pires, "Canine mammary tumours as a model to study human breast cancer: most recent findings,' In Vivo, vol. 25, no. 3, pp. 455-465, 2011.

[74] J. Pérez, M. J. Day, and E. Mozos, "Immunohistochemical study of the local inflammatory infiltrate in spontaneous canine transmissible venereal tumour at different stages of growth," Veterinary Immunology and Immunopathology, vol. 64, no. 2, pp. 133-147, 1998.

[75] P. K. Nicholls, P. F. Moore, D. M. Anderson et al., "Regression of canine oral papillomas is associated with infiltration of CDA+ and CD8+ lymphocytes," Virology, vol. 283, no. 1, pp. 31-39, 2001.

[76] G. L. Cockerell and D. O. Slauson, "Patterns of lymphoid infiltrate in the canine cutaneous histiocytoma," Journal of Comparative Pathology, vol. 89, no. 2, pp. 193-203, 1979.

[77] V. Grieco, M. Rondena, S. Romussi, D. Stefanello, and M. Finazzi, "Immunohistochemical characterization of the leucocytic infiltrate associated with canine seminomas," Journal of Comparative Pathology, vol. 130, no. 4, pp. 278-284, 2004.

[78] A. Estrela-Lima, M. S. S. Araújo, J. M. Costa-Neto et al., "Immunophenotypic features of tumor infiltrating lymphocytes from mammary carcinomas in female dogs associated with prognostic factors and survival rates," BMC Cancer, vol. 10, article 256, 2010.

[79] J.-H. Kim, C.-H. Yu, J.-Y. Yhee, K.-S. Im, and J.-H. Sur, "Lymphocyte infiltration, expression of interleukin (IL)-1, IL6 and expression of mutated breast cancer susceptibility gene1 correlate with malignancy of canine mammary tumours," Journal of Comparative Pathology, vol. 142, no. 2-3, pp. 177-186, 2010.

[80] M. I. Carvalho, I. Pires, J. Prada, and F. L. Queiroga, “T-lymphocytic infiltrate in canine mammary tumours: clinic and prognostic implications," In Vivo, vol. 25, no. 6, pp. 963-969, 2011.

[81] K. Saeki, Y. Endo, K. Uchida, R. Nishimura, N. Sasaki, and T. Nakagawa, "Significance of tumor-infiltrating immune cells in spontaneous canine mammary gland tumor: 140 cases," Journal of Veterinary Medical Science, vol. 74, no. 2, pp. 227-230, 2012.

[82] J. H. Kim, J. H. Hur, S. M. Lee, K. S. Im, N. H. Kim, and J. H. Sur, "Correlation of Foxp3 positive regulatory T cells with prognostic factors in canine mammary carcinomas," Veterinary Journal, vol. 193, pp. 222-227, 2012.

[83] J. H. Kim, S. K. Chon, K. S. Im, N. H. Kim, and J. H. Sur, "Correlation of tumor-infiltrating lymphocytes to histopathological features and molecular phenotypes in canine mammary carcinoma: a morphologic and immunohistochemical morphometric study," Canadian Journal of Veterinary Research, vol. 77, pp. 142-149, 2013.

[84] G. Knowles, B. W. O'Neil, and M. S. Campo, "Phenotypical characterization of lymphocytes infiltrating regressing papillomas," Journal of Virology, vol. 70, no. 12, pp. 8451-8458, 1996.

[85] I. Pires, F. L. Queiroga, A. Alves, F. Silva, and C. Lopes, "Decrease of E-cadherin expression in canine cutaneous histiocytoma appears to be related to its spontaneous regression," Anticancer Research, vol. 29, no. 7, pp. 2713-2717, 2009.

[86] Y. Horiuchi, A. Hanazawa, Y. Nakajima et al., "T-helper (Th) 1/ Th2 imbalance in the peripheral blood of dogs with malignant tumor," Microbiology and Immunology, vol. 51, no. 11, pp. 11351138, 2007.

[87] S. Gupta, K. Joshi, J. D. Wig, and S. K. Arora, "Intratumoral FOXP3 expression in infiltrating breast carcinoma: its association with clinicopathologic parameters and angiogenesis," Acta Oncologica, vol. 46, no. 6, pp. 792-797, 2007.

[88] D. Mougiakakos, A. Choudhury, A. Lladser, R. Kiessling, and C. C. Johansson, "Regulatory T cells in cancer," Advances in Cancer Research, vol. 107, pp. 57-117, 2010. 
[89] B. J. Biller, R. E. Elmslie, R. C. Burnett, A. C. Avery, and S. W. Dow, "Use of FoxP3 expression to identify regulatory T cells in healthy dogs and dogs with cancer," Veterinary Immunology and Immunopathology, vol. 116, no. 1-2, pp. 69-78, 2007.

[90] B. J. Biller, A. Guth, J. H. Burton, and S. W. Dow, "Decreased ratio of $\mathrm{CD} 8+\mathrm{T}$ cells to regulatory $\mathrm{T}$ cells associated with decreased survival in dogs with osteosarcoma," Journal of Veterinary Internal Medicine, vol. 24, no. 5, pp. 1118-1123, 2010.

[91] J. H. Kim, S. K. Chon, K. S. Im, N. H. Kim, K. W. Cho, and J. H. Sur, "Infiltrating Foxp3+ regulatory T cells and histopathological features in canine classical and spermatocytic seminomas," Reproduction in Domestic Animals, vol. 48, pp. 218-222, 2013.

[92] R. Kumaraguruparan, D. Prathiba, and S. Nagini, "Of humans and canines: immunohistochemical analysis of PCNA, Bcl-2, p53, cytokeratin and ER in mammary tumours," Research in Veterinary Science, vol. 81, no. 2, pp. 218-224, 2006.

[93] M. C. Paoloni and C. Khanna, "Comparative oncology today," Veterinary Clinics of North America, vol. 37, no. 6, pp. 1023-1032, 2007.

[94] P. Uva, L. Aurisicchio, J. Watters et al., "Comparative expression pathway analysis of human and canine mammary tumors," BMC Genomics, vol. 10, article 135, 2009.

[95] K. Lindblad-Toh, C. M. Wade, T. S. Mikkelsen et al., "Genome sequence, comparative analysis and haplotype structure of the domestic dog," Nature, vol. 438, no. 7069, pp. 803-819, 2005.

[96] F. Joy, S. Basak, S. K. Gupta, P. J. Das, S. K. Ghosh, and T. C. Ghosh, "Compositional correlations in canine genome reflects similarity with human genes," Journal of Biochemistry and Molecular Biology, vol. 39, no. 3, pp. 240-246, 2006.

[97] A. Ben-Baruch, "Breast cancer progression: a "Vicious Cycle" of pro-malignancy activities is mediated by inflammatory cells, chemokines and cytokines," in Integration/Interaction of Oncologic Growth, pp. 189-217, Springer, Amsterdam, The Netherlands, 2005.

[98] F. Balkwill and A. Mantovani, "Inflammation and cancer: back to Virchow?" The Lancet, vol. 357, no. 9255, pp. 539-545, 2001.

[99] G. Curigliano, G. Spitaleri, E. Petri et al., "Breast cancer vaccines: a clinical reality or fairy tale?” Annals of Oncology, vol. 17, no. 5, pp. 750-762, 2006.

[100] B. Acres, J. Limacher, and J. Bonnefoy, "Discovery and development of therapeutic cancer vaccines," Current Opinion in Drug Discovery and Development, vol. 10, no. 2, pp. 185-192, 2007. 


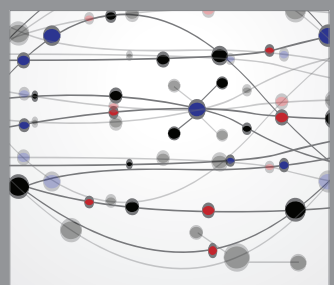

The Scientific World Journal
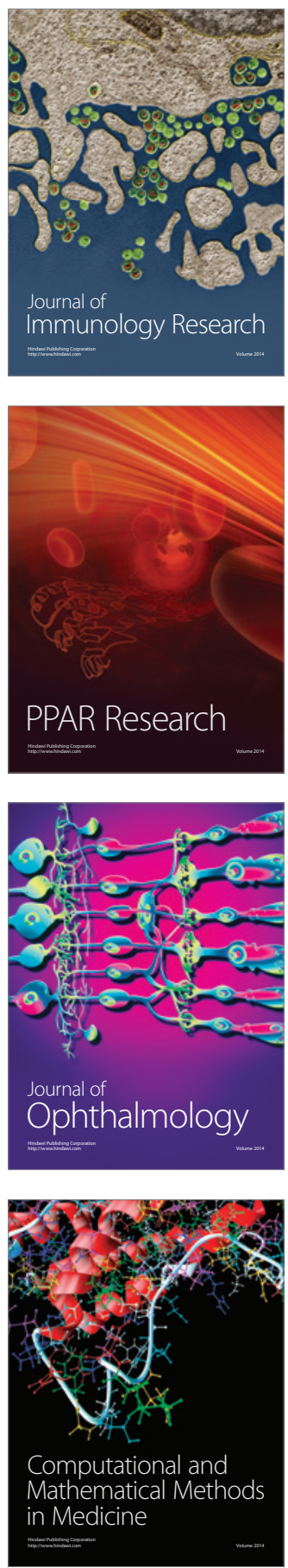

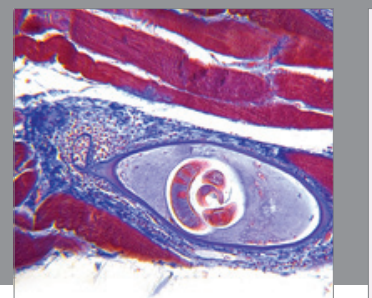

Gastroenterology

Research and Practice
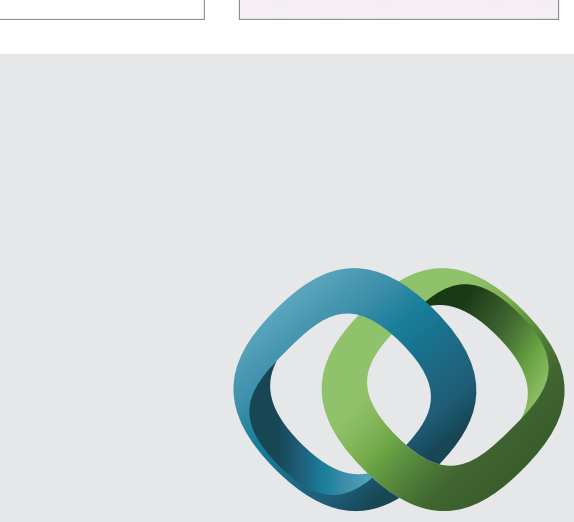

\section{Hindawi}

Submit your manuscripts at

http://www.hindawi.com
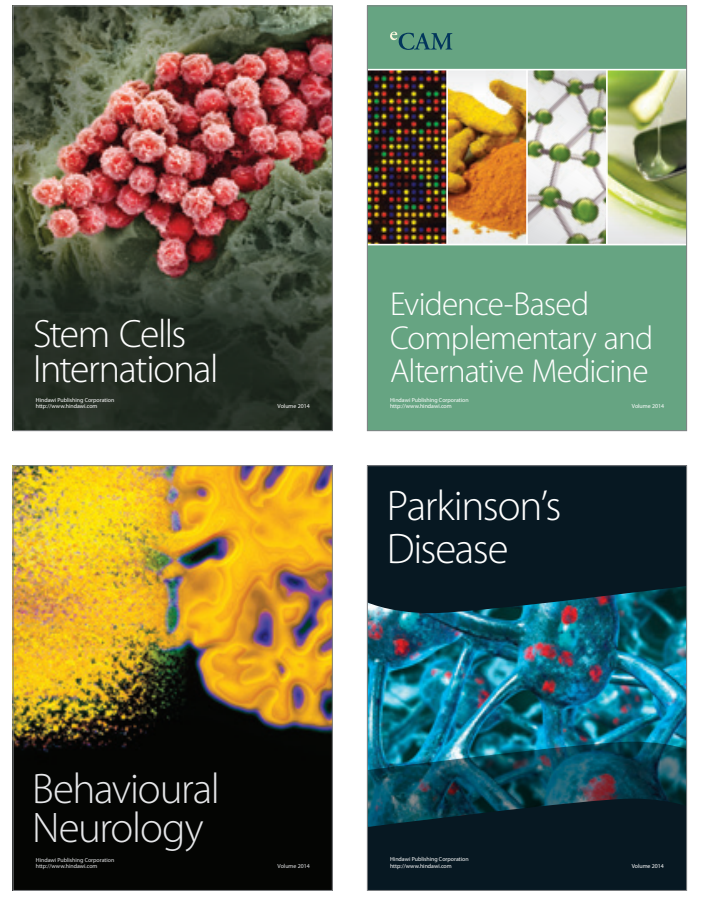
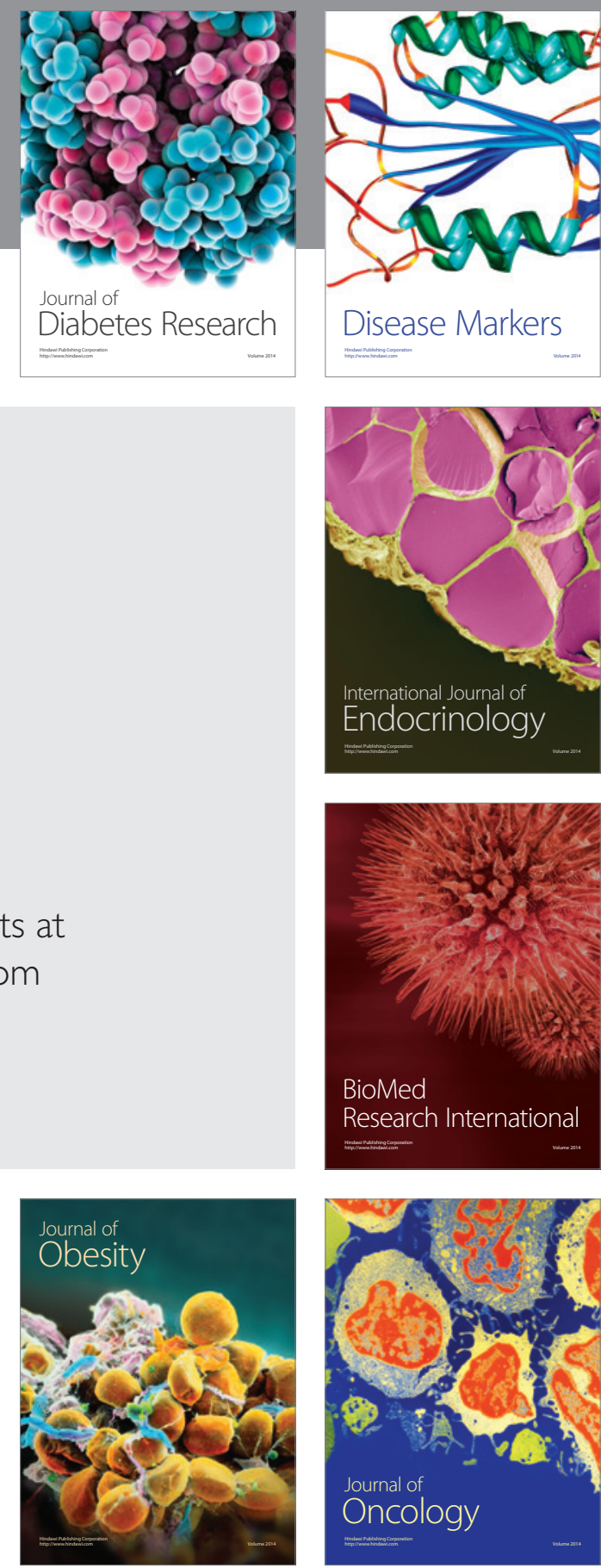

Disease Markers
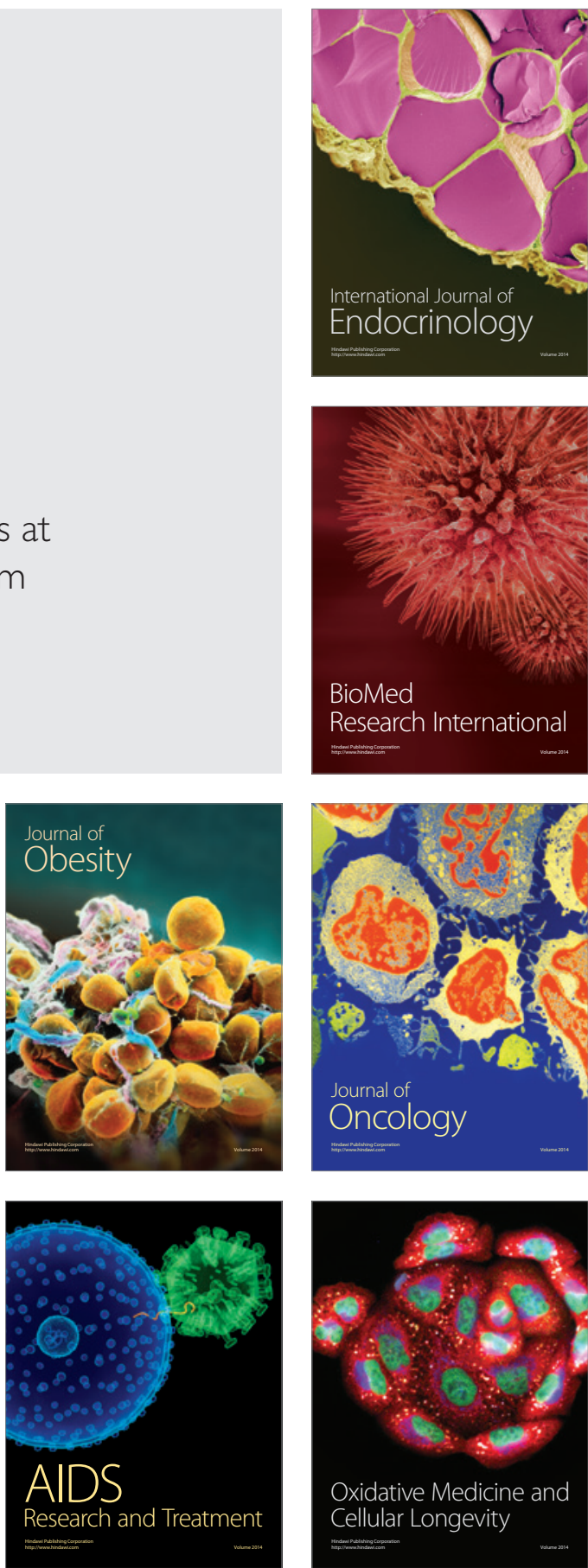